\title{
Extreme sea levels under present and future climate: a pan-European database
}

\author{
Dominik Paprotny ${ }^{1, a}$, Oswaldo Morales-Nápoles ${ }^{1}$ and Grigory Nikulin ${ }^{2}$ \\ ${ }^{1}$ Delft University of Technology, Faculty of Civil Engineering and Geosciences, Stevinweg 1, 2628 CN Delft, The Netherlands \\ ${ }^{2}$ Swedish Meteorological and Hydrological Institute, Rossby Centre, SE-601 76 Norrkoping, Sweden
}

\begin{abstract}
Continental or global studies of coastal flood hazard in the context of climate change encounter several obstacles. The primary concern is the limited coverage of sea level data, especially the high-frequency sort needed to analyse sea level extremes. In this paper we present the calculations of return periods of storm surge heights and water levels for the European coast. The analysis utilized simulations using Delft3D hydrodynamic model driven by meteorological data with temporal and spatial resolution, created under EURO-CORDEX activities. The simulations were calibrated using short- and long-term sea levels from over 150 gauges. Annual maxima of water levels were extracted from five simulations: 1971-2000 historical run as well as 2021-50 and 2071-2100 simulations based on two emissions scenarios each. Spatially varying sea level rise projections were also included. Annual maxima were then fitted to probability distributions in order to obtain the return periods. The results were combined with more than 70,000 coastal sections, so that they would be complimentary with a river flood hazard dataset developed in parallel. The study showed a good match between simulated and observed storm surge heights. It also shows large differences in future trends of water levels in Europe.
\end{abstract}

\section{Introduction}

The main weather-related hazard in seaside areas are increases of water levels caused by windstorms, which may result in breaching of coastal defences and flooding. Though storm surges rarely cause such outcome, the consequences are often disastrous when they occur. Indeed, a list of large floods in Europe for 1950-2005 [1] includes only three coastal floods compared to 44 river and flash floods; yet, ranked by number of casualties, storm surges come first, third and sixth. The biggest was the 1953 North Sea flood, which caused over 2,000 casualties in the Netherlands and Belgium. That storm surge also resulted in 546 deaths in the United Kingdom, while the 1962 Hamburg flood killed 347 persons. The most recent large coastal flood occurred in 2010 in western France, with a death toll of 41 [2].

There is large concern that those rare events are becoming much more frequent because of the global climate change. One contributing factor would be an increase in storminess. Though no general trends have been detected in either historical data or climate projections, large regional variations are indicated $[3,4]$. A crucial factor is the increase of the mean sea level (MSL), which is considered to translate directly into higher storm surge frequency [3, 5-7]. Between 1880 and 2009, global MSL increased by $21 \mathrm{~cm}$ [8], while IPCC projections show a further increase of $28-98 \mathrm{~cm}$ by 2100 [3]. However, sea level rise (SLR) is hardly uniform, according to recent satellite altimetry [9]. For instance in the North Sea the 1992-2015 trend was $1.8 \mathrm{~mm}$ per year, lower than the global average of $2.9 \mathrm{~mm}$ per year. In contrast, the trend in the Baltic Sea was $3.3 \mathrm{~mm}$ per year. In NOAA's data [9] even negative trends could be found for some small parts of the seas surrounding Europe.

Nevertheless, climate change is not the only factor influencing the level of hazard over time. One is glacial isostatic adjustment (GIA), the rebound of Earth's crust after the melting of ice sheets that covered vast areas during the last Ice Age. In Europe, its main effect is the vertical movement of the ground. In Scandinavia and in most other northernmost parts of Europe it causes an uplift, which can reach up to $1 \mathrm{~cm}$ per year in the northern part of the Gulf of Bothnia. For the time being, it effectively counters SLR along coasts of Sweden or Finland. More globally, ocean basins are becoming bigger due to GIA, slightly reducing sea level rise [10, 11]. Finally, there are various local factors generating vertical ground motion. More often than not, subsidence occurs, exacerbating the effects of SLR [12].

The main direct source of information on water levels during storm surges are high-frequency tide gauge measurements. Unfortunately, their availability is limited, not only because of the relative scarcity of the tide gauge network, but also due to limited dissemination of this data. Few countries consider this information as open data and make all the historical series freely available. Shortage is particularly acute when we consider that at

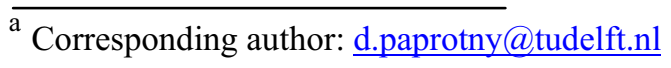


least a 30-year series is considered necessary for calculating return periods from annual maxima.

In effect, various methods have been used in order to increase the coverage of extreme water level estimates, so that a complete, continuous dataset along the coastline can be created. One group of approaches are statistical methods. The simplest is to make a geostatistical interpolation between tide gauges. One study [13] created maps of storm surge return periods in the Baltic Sea using this method. This basin, however, has the convenient feature of having negligible tides. Therefore, a study of the Atlantic coast of France [14] supplemented interpolation of surge levels with tidal amplitudes from a dedicated tide model. Then, there is a regional frequency analysis (RFA) method, which aims at identifying spatial patters in the probability distribution of storm surges in nearby gauges. It was originally developed by [15] and used in several studies, e g. in France [16,17] and the Netherlands [18].

Those methods, though, still require considerable amount of data from measurements. Therefore, many studies use hydrodynamic modelling instead. Here, such a model representing the basin in question is set up and then forced by wind and air pressure from observations or climate models. In this way, the water levels can be derived for the entire domain, including the influence of coastal features, bathymetry, climate or tides. Several studies of different parts of Europe have been performed. They used various techniques and model set-ups, with focus put on different aspects. For instance, one study made a general hindcast of water levels in the western coasts of Europe [19], while another concentrated on future climate change impacts on storm surges in the Netherlands [4]. Meanwhile, a different study [20] developed estimates of extreme water levels along Great Britain's coast by correcting the output from the hydrodynamic model using a statistical analysis at tide gauges. Similarly, another group [21] combined numerical models with RFA for the North Sea coast of Germany. Notwithstanding the method used, only a handful of studies analysed the subject on a European or global scale.

Until recently, the main source of this information was the Dynamic Interactive Vulnerability Assessment (DIVA) global database [22, 23], now succeeded by a bigger model CFFlood [24]. They have the advantage of providing information for an average $\sim 70 \mathrm{~km}$ segment of the coast. However, the return periods of floods were based on simple assumptions and not well documented. Most recently, there was an attempt to fill the gap by creating a global hindcast of sea levels with hydrodynamic modelling [25]. The study applied a Delft3D model forced by ERA-Interim climate reanalysis, covering years 1979-2014. Though it showed good accuracy for modelling the surge, the focus was put on the quality of sub-daily/daily predictions and the calibration was performed on the deep ocean. Only limited validation for the European coast was presented, with only ten gauges used for that purpose, of which four were located in the Canary Islands and the Azores. Another study is currently being carried out by the Joint Research Centre (JRC) in Ispra [26]. It covers Europe and focuses on changes in coastal flood hazard in the future, taking into consideration changes in storm surge and wave regime, together with sea level rise. Storm surge heights are obtained from hydrodynamic modelling, while tidal amplitude was taken from an external model.

From this brief summary it is noticeable that a panEuropean coastal hazard study based on a wind-driven model haven't been performed so far, bar the ongoing research at JRC. In this study, we undertake such an analysis, creating a database of extreme water levels necessary to make flood hazard maps under present and future climate. Most importantly, the output was intended to be complimentary to a set of hydrological and meteorological hazard maps created in "Risk analysis of infrastructure networks in response to extreme weather" (RAIN) project. The study in especially close alignment to river flood hazard study performed in parallel [27]. In this common framework, all European Union countries are covered in the study. EURO-CORDEX climate simulations are utilized [28] to create a hindcast of return periods of hazards (1971-2000) together with two climate change scenarios for two time period each (20212050 and 2071-2100). The database and the resulting hazard maps will be freely available as a result of the project, so that they can be used by other researchers.

The paper is structured as follows. Section 2 explains the datasets incorporated into the study and outlines the methodology of hydrodynamic modelling and calculation of return periods. Section 3 presents first the results of model validation at tide gauges, then shows the overview of storm surge and water level return periods for Europe, and finally briefly discusses the future changes in the hazard level. In section 4 the limitations of the study are discussed together with a comparison of the accuracy of the results with other analyses and overview of further research steps, before the conclusions are drawn in section 5 .

\section{Materials and methods}

The study required gathering of many types of data. Firstly, meteorological data were obtained to drive the Delft3D model. The model itself was set up with information on bathymetry and calibrated. For that, data from tide gauges were obtained, which also allowed to validate the results. Several additional datasets providing information about tides, glacial isostatic adjustment and sea level rise.

\subsection{Meteorological data}

Two datasets were used here: ERA-Interim climate reanalysis and EURO-CORDEX climate simulations for past and future climate.

First of the aforementioned, ERA-Interim, is a continuously-updated global atmospheric reanalysis, starting with the year 1979 [29]. It has a spatial resolution of $0.75^{\circ}$, or about $80 \mathrm{~km}$ at equator and temporal resolution of 3 hours. In this study we applied it for the purpose of calibrating the hydrodynamic model. Since ERA-Interim uses data assimilation, it can provide 
sufficiently accurate information on temporal development of air pressure and wind speeds/direction, hence allowing for a direct comparison of modelled water levels with tide gauge observations.

The second dataset was generated within the EUROCORDEX activities at the Rossby Centre of the Swedish Meteorological and Hydrological Institute (SMHI). It uses ICHEC-EC-EARTH general circulation model with SMHI-RCA4 regional circulation model [30], realization t12ilp1. This dataset includes 3-hour series of air pressure and 6-hour series of wind speed ( $u$ - and $v$ component). The resolution of the climate data is $0.11^{\circ}$ (about $12 \mathrm{~km}$ ). The model includes a historical run (1970-2005) and two climate projections (2006-2100) using RCP 4.5 and RCP 8.5 scenarios [31].

\subsection{Delft3D and hydrodynamic model set-up}

The study uses Delft3D model by Deltares, which was employed also in some other studies mentioned in the introduction $[25,26]$. The model utilizes depth-averaged shallow water equations and allows to simulate both tides and surges. In this study, however, only the latter was calculated for a number of reasons. First of all, we want the model to accurately represent the annual maxima of storm surges, so that return periods could be calculated. That requires long simulation periods and increased time steps, opposite to what is necessary for proper representation of tides operating in a predominantly semidiurnal cycle. Also, we are mostly interested in the weather-related phenomena. There is, naturally, an interaction between surges and tides, though the calibration of the model was done on skew surge from tide gauge measurements, which includes this interaction (see next section). Furthermore, we analysed the statistical dependency of tides and surges for available stations and concluded that they can be safely assumed independent (see section 2.4).

In the model, we use a structured grid of the same shape and resolution as the $0.11^{\circ}$ EURO-CORDEX domain, with only slightly trimmed extent. That way, only interpolation of the ERA-Interim data was needed while maintaining reasonable resolution. For comparison, one of the studies [25] used an unstructured grid with a resolution of $0.05-0.5^{\circ}$, while the other [26] employed a regular $0.2^{\circ}$ grid. Bathymetry was created from a digital terrain model covering all basin around Europe [32], originally at $0.125^{\prime}$ resolution. The bathymetry was adjusted in several narrow straits in order to properly represent the flow of water though those passages.

We should note that the modelled surge heights are calculated as relative to local mean sea level. Thus, the boundary conditions and initial water level was set to zero. Meanwhile, the time step was set to 30 minutes to keep calculation time in check. For similar reasons the temporal resolution of the input data was chosen as 6 hours, despite air pressure data being available at 3-hour resolution. As a result, the output was also saved at 6hour intervals.

Calibration was primarily done by adjusting two parameters. One is the wind drag coefficient, commonly known as Charnock [33]. Here, the coefficient increases with wind speed from 0.0013 to 0.007 , slightly different than the default value. The other, more sensitive parameter is the bed roughness. Its formulation by Chézy is used here and was defined locally during calibration (IHO maritime divisions from [34] were used as a reference). Particularly large influence of this parameter was recorded in the Danish and Turkish straits as well as Adriatic and North seas. On the other hand, most of the Mediterranean and Atlantic coasts were not too sensitive to it. The calibration runs encompassed years 1997-2000 and 2011-2014. Then, the model was validated with a full 1979-2014 run using ERA-Interim, and finally for 1970-2005 utilizing EURO-CORDEX data. The materials and measures used for calibration and validation are discussed in the next section.

\subsection{Tide gauge data and validation procedure}

For comparison between modelled and observed water levels, data from available tide gauges were collected. The dataset compiled here consists of three parts. The primary set of research-quality high-frequency observations consists of 90 stations. That includes 21 stations from 12 countries obtained from University of Hawaii Sea Level Center [35], 42 stations (all but three in the UK) from the British Oceanographic Data Centre [36], 19 Swedish stations from the SMHI [37] and 8 Dutch stations from Rijkswaterstaat [38]. Most of the stations have long series of data covering the entire period of interest (1970-2014). The secondary set consists of high-frequency raw data from 66 Mediterranean stations obtained from the Joint Research Centre. They mostly cover years 2011-2014, with some series stretching back to 2008. Additionally, 5 Polish stations containing only information on annual maxima were used for validation of full model runs (obtained from [39]). The locations of all stations are presented in Fig. 1.

As we noted in the previous section, surge levels are modelled as values relative to MSL. Therefore, sea level observations for each station were detrended and the long-term MSL was subtracted. A basic quality check was done for the stations from the secondary set, as some stations contained visibly erroneous observations. Afterwards, tides were removed from the water levels. Here, we opted to calculate the skew surge, i.e. the difference between the predicted astronomical high tide and nearest observed high water [20]. This approach gives more certainty than using the residual, as even a very small difference in timing of the predicted and actual tide creates an "illusory" surge [40].

Predicted tide levels were obtained mostly through harmonic analysis, though predictions by the International Hydrographic Organization (IHO; prepared via Delft Dashboard software) were used instead for some ocean-exposed stations, as they gave better results. Additionally, for some stations in Sweden (Stockholm and all other located northwards) water level data was applied directly, since a harmonic analysis actually created additional noise. This is likely because of the very 
low tidal amplitudes in that region. For the Mediterranean, JRC's calculations were used for the tides, except for gauges were the quality check caused many modifications to the raw data.

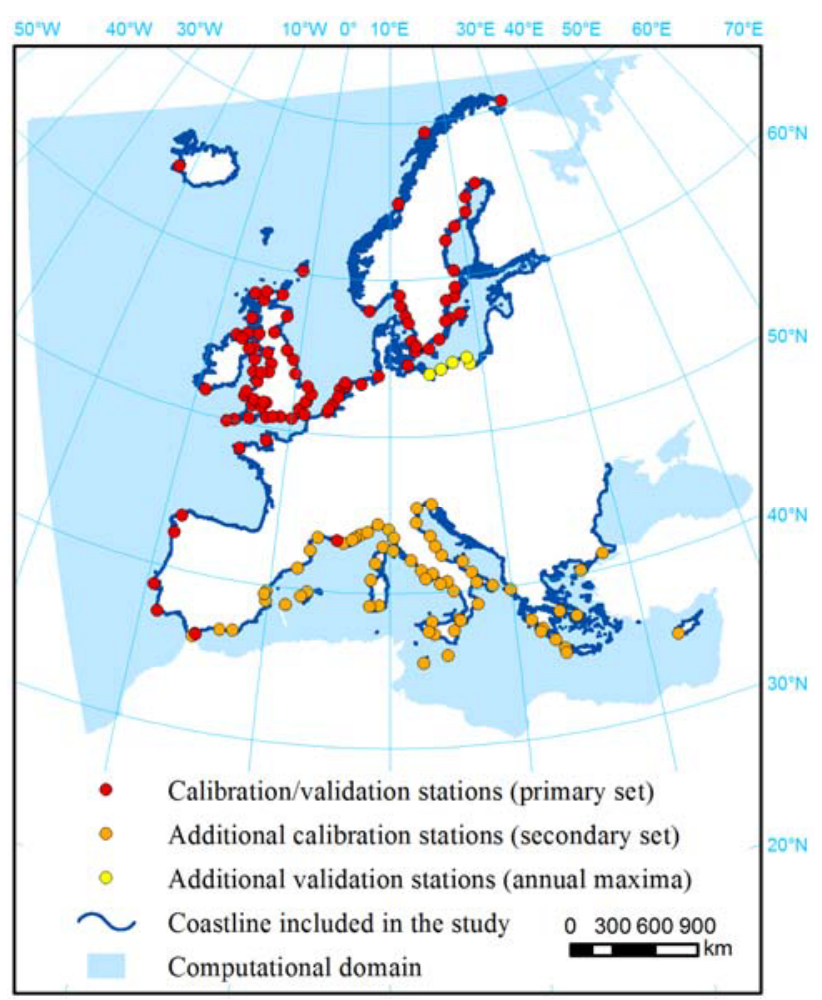

Figure 1. The domain used in Delft3D simulation and location of tide gauge stations used for calibration and validation.

During calibration three series of water levels were analysed: 6-hour values, daily maxima and monthly maxima. Each was evaluated with a set of measures. They are: Pearson's coefficient of determination $\left(\mathrm{R}^{2}\right)$, Nash-Sutcliffe efficiency (NSE), root mean square error (RMSE) and RMSE-observations standard deviation ratio (RSR). The popular $\mathrm{R}^{2}$ does not need further introduction. NSE is a measure that indicates bias of the model. Its maximum value is 1 , which means a plot of observed vs simulated data fits the 1:1 line, while value below 0 (down to $-\infty$ ) indicates that the mean is a better predictor than the simulated value. It is calculated using eq. 1:

$$
N S E=1-\left[\frac{\sum_{i=1}^{n}\left(X_{i}^{o b s}-X_{i}^{\text {sim }}\right)^{2}}{\sum_{i=1}^{n}\left(X_{i}^{o b s}-X^{\text {mean }}\right)^{2}}\right]
$$

where $X_{i}{ }^{o b s}$ is the $i$-th observation of a variable, $X_{i}{ }^{\text {sim }}$ is the $i$-th simulated value of that variable and $X^{\text {mean }}$ is the mean of observations.

RMSE measures the error in the units of observation. Meanwhile, RSR relates the RMSE to the standard deviation of observations $\left(S D_{o b s}\right)$, thus standardizing the RMSE:

$$
R S R=\frac{R M S E}{S D_{o b s}}=\frac{\sqrt{\sum_{i=1}^{n}\left(X_{i}^{o b s}-X_{i}^{s i m}\right)^{2}}}{\sqrt{\sum_{i=1}^{n}\left(X_{i}^{o b s}-X^{\text {mean }}\right)^{2}}}
$$

For details on the aforementioned methods we refer to [41].

\subsection{Extreme water levels}

After storm surge simulations have concluded, extreme water levels were calculated taking into account several factors. The following formula was employed to estimate water levels $W L_{p, T}$ with the probability of occurrence $p$ at time period $T$ :

$$
W L_{p, T}=\text { Surge }_{p, T}+\text { Tide }+M S L_{\text {base }}+S L R_{T}+G I A_{T}
$$

As mentioned in the introduction, the time periods $T$ are 1971-2000, 2021-2050 and 2071-2100. The first component of eq. 3 is the skew surge level Surge $_{p, T}$ at given probability of occurrence. It was calculated by fitting a parametric probability distribution to water levels from model simulations for all time periods. We used two techniques: the block maxima method with Gumbel distribution as well as peak-over-threshold analysis with Generalized Pareto (GP) distribution [42, 43]. Gumbel distribution was chosen for the first method because it performed best in the Akaike Information Criterion goodness-of-fit test applied to our observational dataset [44]. It should be noted that the same method is used in the river discharge analysis. Meanwhile, peakover-threshold method is used here to provide comparison with the JRC study. The skew surge is calculated as follows:

$$
\begin{array}{r}
\text { Surge }_{p, T, \text { Gumbel }}=\alpha-\beta \ln (-\ln (1-p)) \\
\text { Surge }_{p, T, \text { GPareto }}=\mu+\frac{\sigma\left(\left(\frac{-1}{p-1}\right)^{\theta}-1\right)}{\theta}
\end{array}
$$

where $\mu$ is the location parameter in the GP distribution ( $\alpha$ in Gumbel distribution), $\sigma$ is the scale parameter in GP ( $\beta$ in Gumbel) and $\theta$ the shape parameter in GP. In the Generalized Pareto distribution, $\mu$ is defined manually as a threshold value. It was set to the 98.5th percentile of daily maxima of surge levels, which translates to about five events per year, similarly to the JRC study.

Next important factor is the tide height Tide. Having in mind the possibility of tide-surge interaction, we analysed the dependency of the two through copulas. A copula is, in short, a joint distribution on the unit hypercube with uniform $(0,1)$ margins [45]. A series of skew surge heights comprised of the $95^{\text {th }}$ percentile of the whole set was compared with corresponding high tides for all 156 stations. Spearman's rank correlation coefficient was mostly near zero, with 129 stations indicating values less than 0.1. All but two of the 
remainder were Mediterranean stations were tidal amplitudes are very low and the amount of data was much smaller. We also found that the value of tidal amplitude at a station had no influence on the strength of the tide-surge dependency. Therefore, independence of the tides and surges was assumed, and for calculating the coastal hazard the mean high tide was used. This information was obtained from TPXO8 tide model [46], shown to be the most accurate available [47]. It provides 9 constituents in $1 / 30^{\circ}$ resolution $(\mathrm{K} 1, \mathrm{~K} 2, \mathrm{M} 2, \mathrm{M} 4, \mathrm{~N} 2$, $\mathrm{O} 1, \mathrm{P} 1, \mathrm{Q} 1, \mathrm{~S} 2)$ and 4 in $1 / 6^{\circ}$ resolution (MS4, MN4, MF, MM). The same values are used for each time period. It should be noted that despite some studies showing influence of SLR on tides, most concluded that the effect is negligible (see [48] for an overview).

The third element of eq. 3 is the "baseline" mean sea level $M S L_{\text {base }}$. Theoretically, mean sea levels should be aligned to the geoid. In practice, they deviate due to ocean circulation and atmospheric factors. This parameter is a correction for this fact and was obtained from MDT_CNES-CLS13 dataset [49, 50]. It is based on satellite altimetry observations and includes MSL averaged for years $1993-2012$ at $0.25^{\circ}$ resolution. Thus, the fourth constituent of eq. 3 , which is the sea level rise $S L R_{T}$, had to be related to that baseline. SLR includes several factors: changes in dynamic sea topography, steric change (mainly thermal expansion) as well contributions of groundwater, glaciers and ice sheets. The dynamic and steric component were derived from CNRM-CM5 model [51]. It includes European inner seas (omitted in many other models) and has better accuracy for representing the dynamic topography compared to other models [52]. The horizontal resolution of the model is variable, but mostly ca. $0.5^{\circ}$ over Europe. Remaining factors were obtained from studies on regional sea level rise [52, 53], which provided estimates for years 19862100 at $1^{\circ}$ resolution. 1986-2005 trend was extrapolated back to 1971 in order to provide data for the historical scenario.

The fifth and final component is the glacial isostatic adjustment $\left(G I A_{T}\right)$. The combined yearly rate of radial displacement and effects of the glacial rebound on the water level was obtained from ICE-6G_C (VM5a) model [11]. It is a global product with a $1^{\circ}$ resolution. For each time period, the average displacement from the baseline elevation was calculated. This baseline is not the same as in the previous component, but is rather related with the specification of the digital elevation model EU-DEM, which will be used in the future to create flood hazard maps. EU-DEM was made using EVRS2000 vertical reference system, where the eponymous year 2000 is used as its epoch [54].

The calculation of water levels was done for each coastal segment. Those were derived from CCM2 database [55], which defines around 70,000 sections of the coast in our study area. We use this source to be complimentary with the river flood maps developed in RAIN project [27]. Since all datasets used in eq. 3 are grids of different resolutions, information was assigned to each coastal segment from the nearest grid point of each dataset. Such a combined layer of water levels under present and future will be used to calculate flood hazard along the coast. The maps themselves are not presented here in order to provide more in-depth information on the boundary conditions needed for such an analysis.

\section{Results}

\subsection{Calibration and validation results}

Summarized performance of the model after calibration with ERA-Interim climate data is presented in Table 1. "Timeseries" refers to the 6-hour model output compared with the full skew surge series from gauge stations. Results are very good for monthly maxima, less so for daily maxima and the full series. However, the former is most important in context of the work's purpose of obtaining accurate surge levels at different return periods.

\begin{tabular}{|l|l|r|r|r|r|}
\hline \multicolumn{1}{|c|}{ Run } & \multicolumn{1}{|c|}{ Series } & $\mathrm{R}^{2}$ & NSE & RMSE & RSR \\
\hline $\begin{array}{l}\text { 2011-2014 } \\
\text { primary } \\
\text { stations }\end{array}$ & Timeseries & 0.53 & 0.42 & 0.15 & 0.78 \\
\cline { 2 - 6 } $\begin{array}{l}\text { 2011-2014 } \\
\text { secondary } \\
\text { stations }\end{array}$ & Maily max & 0.60 & 0.50 & 0.15 & 0.74 \\
\cline { 2 - 6 } & Timeseries & 0.75 & 0.72 & 0.15 & 0.53 \\
\cline { 2 - 6 } $\begin{array}{l}2011-2014 \\
\text { all stations }\end{array}$ & Daily max & 0.29 & 0.15 & 0.10 & 1.07 \\
\cline { 2 - 6 } & Monthly max & 0.43 & 0.29 & 0.10 & 0.98 \\
\cline { 2 - 6 } & Daily max & 0.48 & 0.36 & 0.13 & 0.86 \\
\cline { 2 - 6 } $\begin{array}{l}\text { 1997-2000 } \\
\text { primary } \\
\text { stations }\end{array}$ & Monthly max & 0.77 & 0.48 & 0.13 & 0.74 \\
\hline \multirow{2}{*}{$\begin{array}{l}\text { 1979-2014 } \\
\text { all stations }\end{array}$} & Daily max & 0.52 & 0.42 & 0.15 & 0.48 \\
\cline { 2 - 6 } & Monthly max & 0.75 & 0.52 & 0.15 & 0.78 \\
\cline { 2 - 6 } & Dimeseries & 0.55 & 0.42 & 0.15 & 0.53 \\
\cline { 2 - 6 } & Monthly max & 0.62 & 0.50 & 0.15 & 0.79 \\
\hline \multirow{2}{*}{ Table } & 0.73 & 0.15 & 0.53 \\
\hline
\end{tabular}

Table 1. Calibration results. See section 2.3 for explanation of measures. RMSE value in meters.

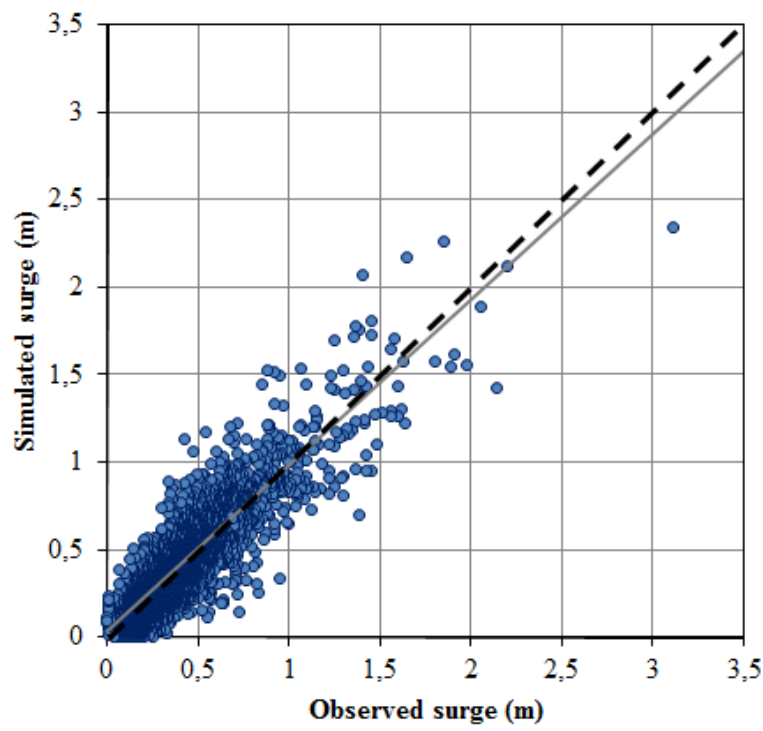

Figure 2. Comparison between simulated and observed monthly maxima (2011-2014). Black dashed line is the 1:1 line, while grey line is the linear regression. 
Most importantly, the model as a whole shows relatively little bias, as can be seen in Fig. 3. Linear regression (indicated by a grey line) applied to monthly maxima deviates only slightly for the dashed black line representing the $1: 1$ relationship.

However, the performance of the model is hardly uniform. Much lower alignment between observed and simulated surge heights was observed at Mediterranean stations (Fig. 2), though surges in those locations are also much smaller than elsewhere in Europe. The model performed best along the southern coasts of the North Sea and in the Danish Straits. Results along the coast of Great Britain are mixed, with relatively low performance observed along the Irish Sea.

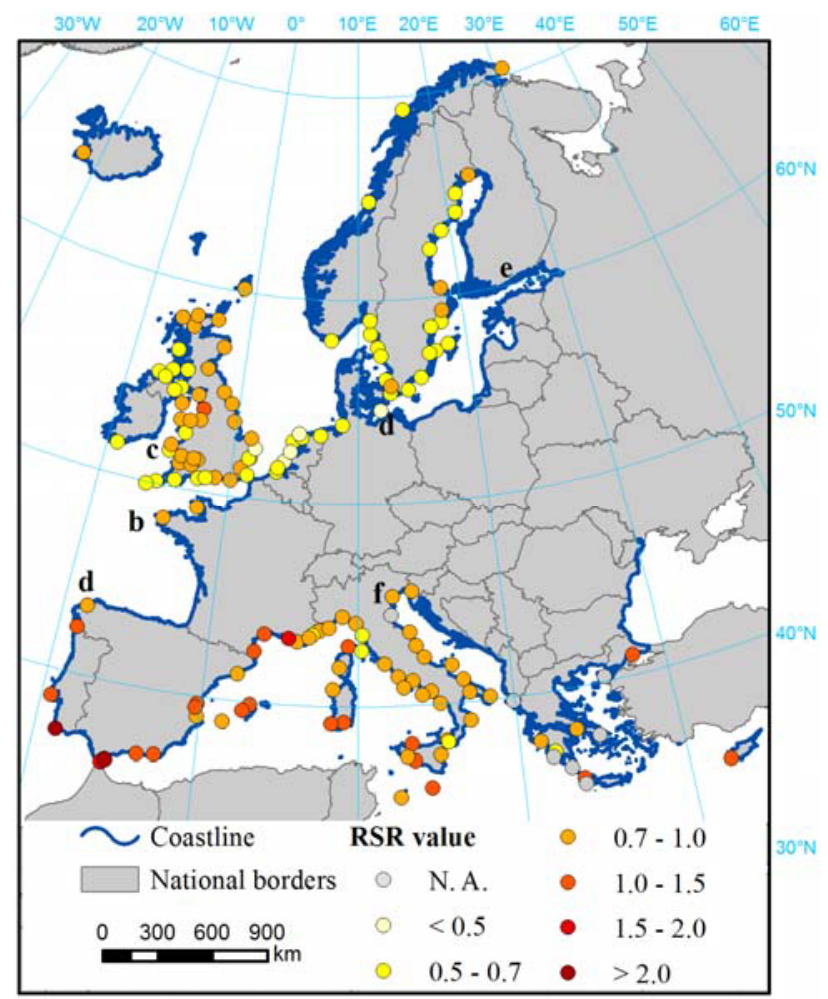

Figure 3. RMSE-observations standard deviation ratio (RSR) for comparison between simulated and observed monthly maxima (2011-2014). N. A. = Not Available.

\begin{tabular}{|c|r|r|r|r|r|r|}
\hline \multirow{2}{*}{$\begin{array}{c}\text { Return } \\
\text { period } \\
\text { (years) }\end{array}$} & \multicolumn{3}{|c|}{$\begin{array}{c}\text { ERA-Interim } \\
\text { (1979-2014) }\end{array}$} & \multicolumn{3}{c|}{$\begin{array}{c}\text { EURO-CORDEX } \\
\mathbf{( 1 9 7 0 - 2 0 0 5 )}\end{array}$} \\
\cline { 2 - 7 } & $\mathbf{R}^{\mathbf{2}}$ & NSE & \multicolumn{1}{c|}{ RSR } & \multicolumn{1}{c|}{$\mathbf{R}^{\mathbf{2}}$} & \multicolumn{1}{c|}{ NSE } & \multicolumn{1}{c|}{ RSR } \\
\hline 1000 & 0.87 & 0.76 & 0.52 & 0.86 & 0.83 & 0.40 \\
\hline 500 & 0.87 & 0.77 & 0.50 & 0.87 & 0.84 & 0.40 \\
\hline 300 & 0.87 & 0.78 & 0.48 & 0.87 & 0.84 & 0.40 \\
\hline 100 & 0.86 & 0.81 & 0.45 & 0.87 & 0.84 & 0.40 \\
\hline 50 & 0.86 & 0.82 & 0.43 & 0.87 & 0.83 & 0.41 \\
\hline 30 & 0.85 & 0.83 & 0.42 & 0.87 & 0.83 & 0.41 \\
\hline 10 & 0.84 & 0.83 & 0.41 & 0.86 & 0.81 & 0.44 \\
\hline 2 & 0.76 & 0.71 & 0.55 & 0.80 & 0.69 & 0.58 \\
\hline
\end{tabular}

Table 2. Validation results (observed vs simulated surge levels). See section 2.3 for explanation of measures.

Similarly to monthly maxima, calculations of annual maxima and return periods using the Gumbel distribution showed good performance, as presented in Table 2. 86 stations with at least 20 years of data were used for comparison with ERA-Interim results and 65 with EURO-CORDEX. Values of the measures change little between different return periods, though they are slightly lower for low probabilities of occurrence. Interestingly, simulation driven by EURO-CORDEX performed mostly better than one based on ERA-Interim data. The results in Table 2 are for different sets of stations, but they are very similar for a common set of 64 stations with sufficient data series. The difference in performance is likely caused by much finer resolution of the EURO-CORDEX model $\left(0.11^{\circ}\right.$ versus $\left.0.75^{\circ}\right)$.

Performance for individual stations is mostly good, as can be seen in examples presented in Fig. 4. In Gedser, Denmark, as well as in many Baltic stations, there is close match of distributions of surges. In Brest there is a mismatch in water levels, both relatively little bias, while in La Coruña station there is noticeable bias. Nevertheless, the overall performance, as presented above, is satisfactory and the full-length simulations for present and future climate could be made.

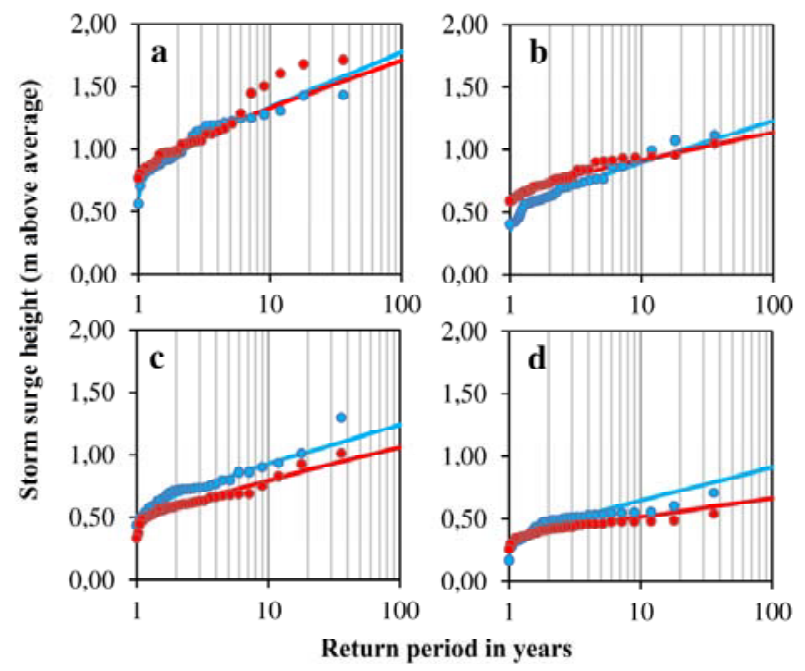

Figure 4. Comparison between simulated (red) and observed (blue) storm surge (1970-2005,) in selected stations. Dots are annual maxima and lines are their probability distributions fitted to Gumbel. Station are: (a) Gedser, Denmark, (b) Milford Haven, UK, (c) Brest, France, (d) La Coruña, Spain (see also Fig. 2).

\subsection{Present and future surge levels in Europe}

After validating the model, simulations of present (1971-2000) and future (2021-50 and 2071-2100) storm surge regime were performed. Results for a 100-year surge are presented in Fig. 5. Surges are the highest in the southern part of the North Sea, up to $4 \mathrm{~m}$, though the average 100-year surge in the Baltic Sea is a bit higher$1.69 \mathrm{~m}$ opposed to an average $1.57 \mathrm{~m}$ for all North Sea coasts. By contrast, in the western Mediterranean Sea and in the Black Sea it mostly amounted to half a metre. In most locations, a 1000-year surge is estimated to be about $50 \%$ higher than a 10 -year surge.

Future trends in storm surge heights are highly uneven. Fig. 6 presents result the change for a 100-year surge, but it is mostly representative for other return periods as well. 


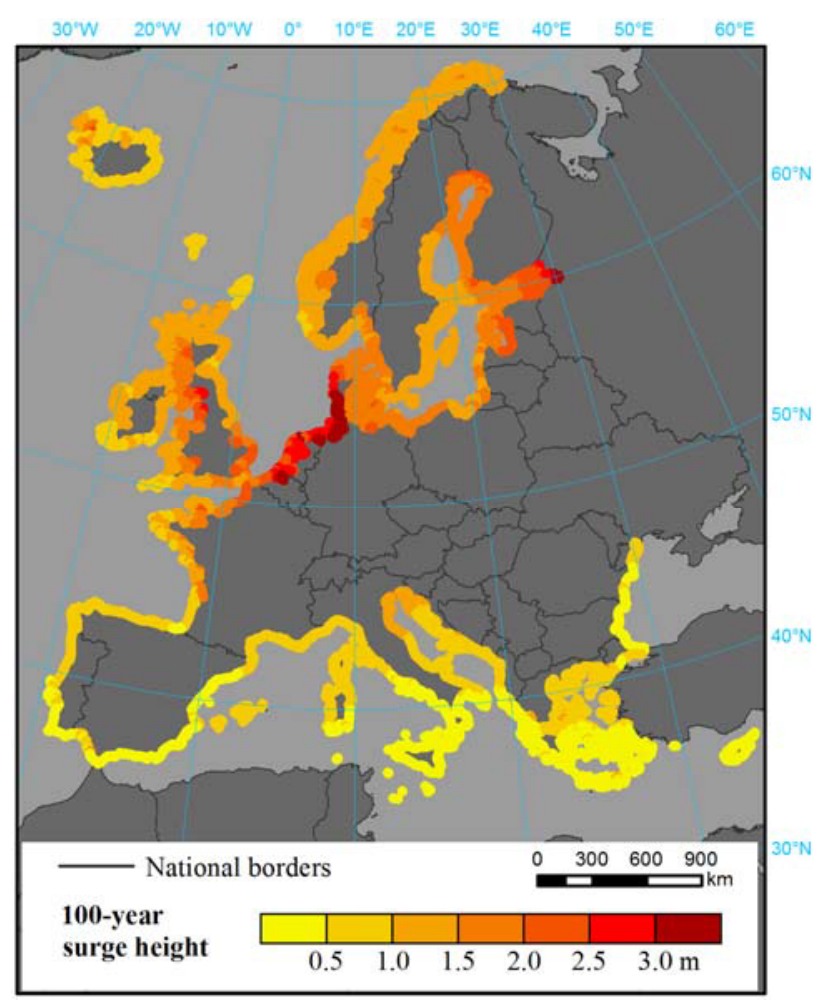

Figure 5. 100-year storm surge height along European coasts, in meters above mean sea level, 1971-2000.

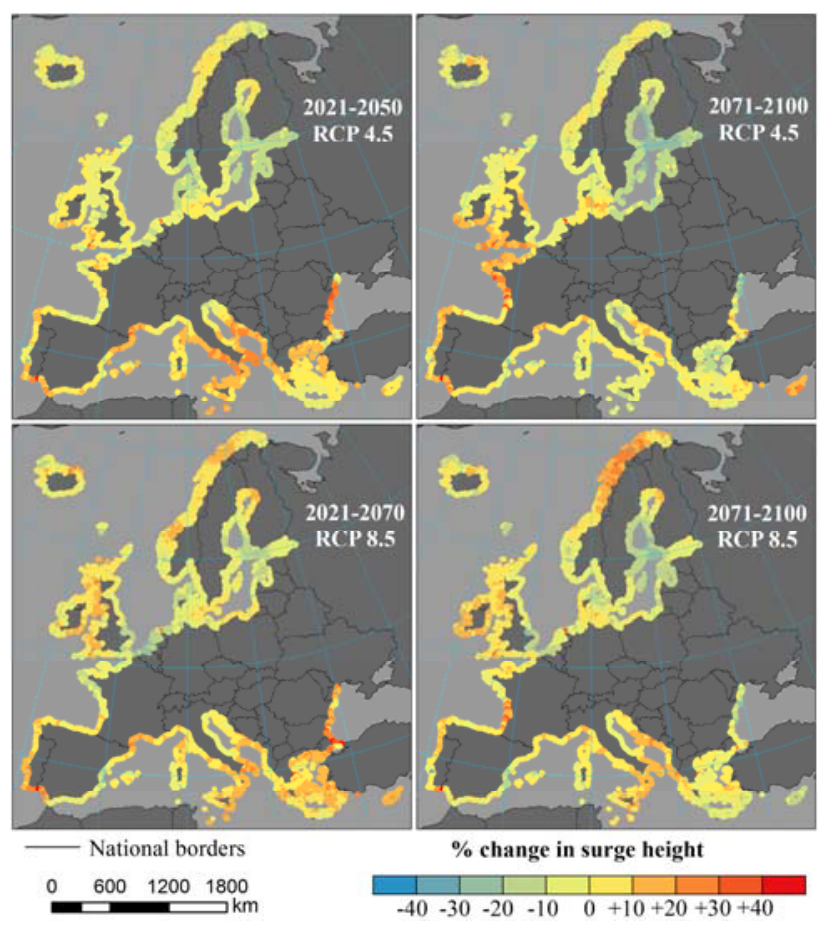

Figure 6. Changes in 100-year storm surge height along European coasts relative to 1971-2000 in \%.

The biggest increases are observed in the Norwegian Sea $-\mathrm{a} 20 \mathrm{~cm}$ rise by $2071-2100$ in RCP 8.5 , though almost no changes were found in this location in RCP 4.5. Relatively large increases were found in the Eastern Mediterranean and Black Sea by 2021-2050, though with large drops in surge heights in the next time period. Bigger storms are also expected in the Gulf of Cadiz, Bay of Biscay and most of British Isles' coast. In the North and Baltic seas, a decrease in storminess is projected.

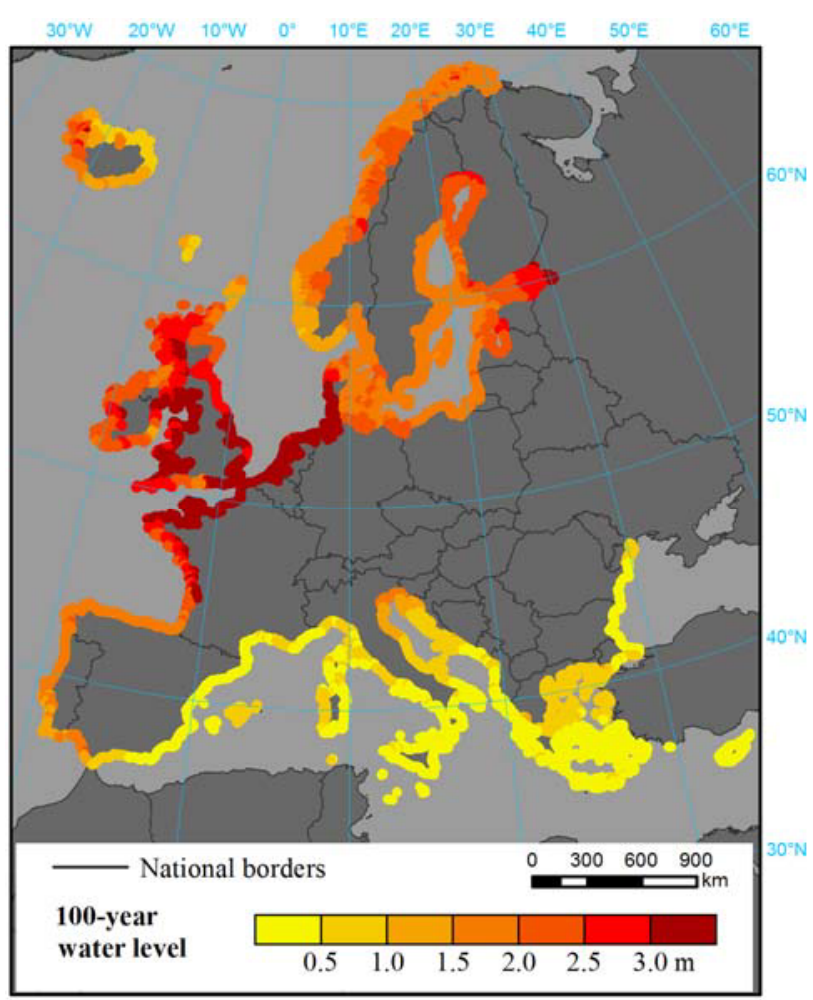

Figure 7. 100-year water level along European coasts, in meters above mean sea level, 1971-2000.

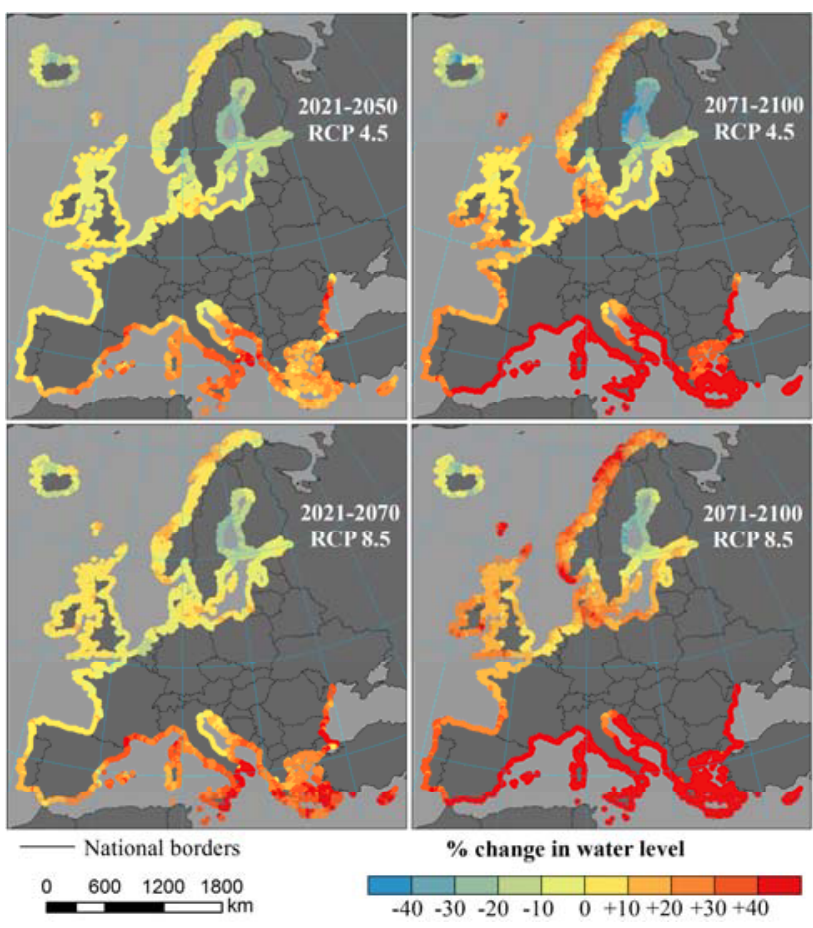

Figure 8. Changes in 100-year water level along European coasts relative to $1971-2000$ in \%.

In the eastern part of the Mediterranean Sea and in the Black Sea there is noticeable increase in surge in the first half of the century, with a drop in the second half. Basically in all areas in RCP 8.5 simulations storms were higher than in RCP 4.5 scenario. Averaged over all coasts in our domain, a 100-year surge was $1.29 \mathrm{~m}$ during 19712000 , declining to $1.20 \mathrm{~m}$ (RCP 4.5) or $1.27 \mathrm{~m}$ (RCP 8.5) by $2071-2100$. Only surges with low return periods (210 years) show a general, albeit small, increase in height 
by mid-century, with 2071-2100 almost the same as during 1971-2000. The same could be observed in most regions, even in the Baltic Sea, where the most extreme surges are projected to decrease.

After including all additional factors (eq. 3), water levels get significantly higher in north-western Europe due to the tides (Fig. 7), where 100-year level can be even $6.5 \mathrm{~m}$ above mean. Still, in most of the Mediterranean region, water levels rarely increase by more $0.5 \mathrm{~m}$. In the almost non-tidal Baltic Sea, 100-year surge amounts to about $2 \mathrm{~m}$.

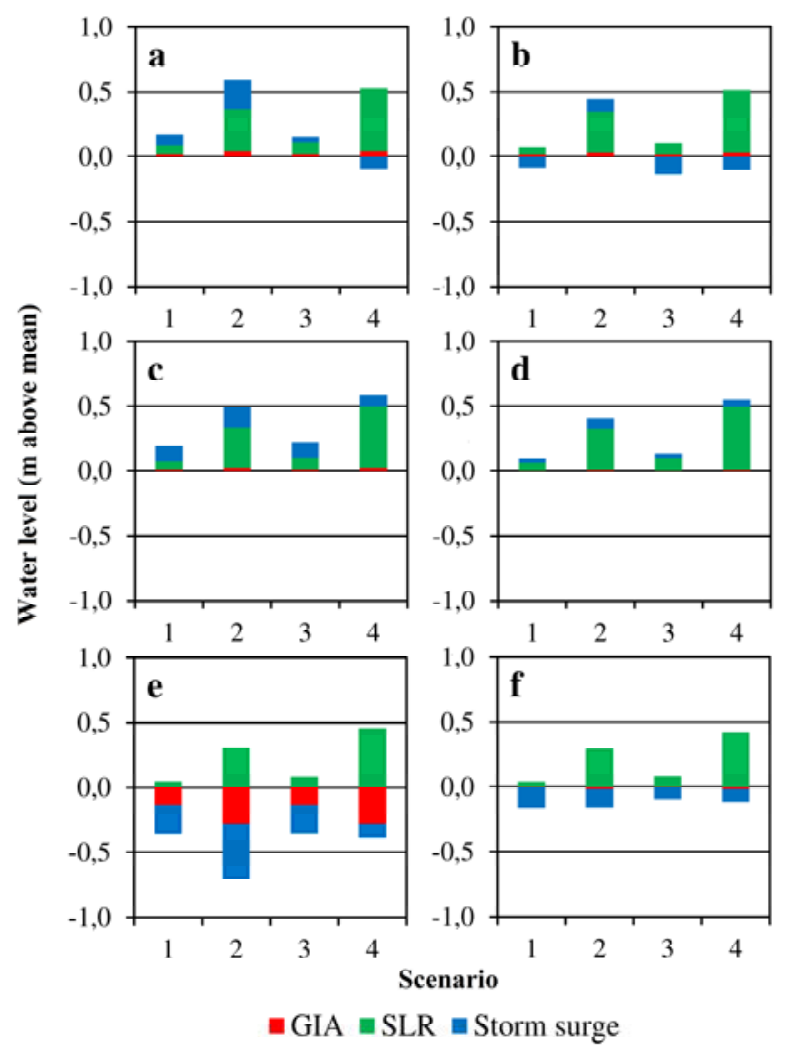

Figure 9. Change in 100-year water levels for selected stations. Stations are: (a) Gedser, Denmark, (b) Milford Haven, UK, (c) Brest, France, (d) La Coruña, Spain, (e) Helsinki, Finland, (f) Venezia, Italy. Scenarios 1 and $3-2021-50 ; 2$ and $4-2071-$ 2100; 1 and 2 - RCP 4.5; 3 and 4 - RCP 8.5.

Increase in water levels in noticeably higher than surges alone in almost all of Europe (Fig. 8). Impact the glacial isostatic adjustment (GIA) is mostly very small, therefore the main source of change in extreme water levels is the sea level rise (SLR). Only in the Baltic Sea the GIA mostly offsets the impact of SLR, even in the RCP 8.5 scenario. Increases are also relatively modest in the northern coasts in the 2021-2050 timeframe, but by 2071-2100 they mostly increase by half a metre. Only the Dutch coast and in some parts of Great Britain will be less affected. It is also projected that along the Norwegian and Iberian coasts, together with the Mediterranean and Black seas, 100-year level will increase by around half a metre in RCP 8.5 by the end of the century. In the Western Mediterranean it will cause a doubling of 100year water levels, and almost tripling of 10-year levels. Largest absolute increases of 100-year levels are expected to be observed in Celtic and Irish seas, $60 \mathrm{~cm}$ and more.
SLR is the main contributing factor almost everywhere, often the only one causing an increase, as opposed to the other two factors we consider (surges and GIA). Examples of influence of different factors for individual stations are presented in Fig. 9.

\section{Discussion}

The analysis includes several sources of uncertainties. Many are related to the input data. Storm surge heights are derived through a hydrodynamic model. Though it was shown that, as a whole, it has good accuracy, performance for individual stations was very diversified. Also, some regions, especially Mediterranean and Black seas or coast of France, had limited or no observational data for comparison. Moreover, the complicated shape of the coast could often not be incorporated, especially shores of Norway, Finland, Greece or Croatia, because the resolution of the model was not fine enough $(\sim 12$ $\mathrm{km})$. Therefore, the error in deriving the surge height could be locally significant. Tides were obtained from a high-resolution model, yet it includes only 13 constituents and may not be as accurate in some regions with diversified coastline. Also, datasets on glacial isostatic adjustment and sea level rise have many times lower resolution than the data on surges or tides. Furthermore, some factors have been omitted. Even though they do not have much relevance in overall, they could be nevertheless important in some localities. That is the case with tide-surge interaction or impact of SLR on tides. We also do not include the influence of ground motion caused by other factors than GIA, as no largescale datasets are available in this aspect. Finally, there is the substantial uncertainty related with climate change, which is well illustrated by the differences in RCP 4.5 and 8.5 scenarios. For one thing, storm surge calculations rely on the predictions of wind speeds/directions and air pressure, while SLR estimates combine several climaterelated phenomena, some not well quantified.

Still, the accuracy of the method presented here could be contrasted with two previous studies. One is the global study mentioned in the introduction [25], even though only six gauges are included both in this study and the aforementioned analysis. Also, it was only possible to make comparison based on the statistics presented by the authors (Table 3 ). $\mathrm{R}^{2}$ for the monthly maxima stand out better than in the other study, which also reports large bias in the model. Though no statistical measures are presented, the graph of monthly maxima indicates that NSE could be even below zero, which is in large contrast to our results (Fig. 3).

\begin{tabular}{|c|c|c|c|}
\hline \multirow[t]{2}{*}{ Measure } & \multicolumn{2}{|c|}{$\begin{array}{l}\text { Muis et al. (2015) - } \\
\text { results for 2007 }\end{array}$} & \multirow{2}{*}{\begin{tabular}{|c} 
This \\
study - \\
2011-2014
\end{tabular}} \\
\hline & Global & Europe & \\
\hline Number of stations & 254 & 10 & 156 \\
\hline RMSE - timeseries & 0.10 & 0.12 & 0.13 \\
\hline $\mathrm{R}^{2}-$ timeseries & 0.45 & 0.74 & 0.48 \\
\hline $\mathrm{R}^{2}-$ daily maxima & 0.54 & 0.76 & 0.55 \\
\hline $\mathrm{R}^{2}-$ monthly maxima & 0.49 & 0.61 & 0.77 \\
\hline
\end{tabular}

Table 3. Comparison of reported validation results (observed vs simulated surge levels) using ERA-Interim data. 
More detailed comparison could be made using directly the results published by the JRC [26]. That study used peak-over-threshold analysis of extreme surges, covering a period from 1 December 1969 to 30 November 2004 (one month shift from this study). Table 4 compares the results for a set of 65 stations using Generalized Pareto distribution. For all return periods, NSE and RSR indicate much better performance, though it decreases with the return period. In effect, for the most extreme surges the correlation is lower in our study; the JRC's is also more consistent between return periods.

\begin{tabular}{|c|r|r|r|r|r|r|}
\hline \multirow{2}{*}{$\begin{array}{c}\text { Return } \\
\text { period } \\
\text { (years) }\end{array}$} & \multicolumn{3}{|c|}{ Joint Research Centre } & \multicolumn{3}{|c|}{$\begin{array}{c}\text { This work (EURO- } \\
\text { CORDEX simulation) }\end{array}$} \\
\cline { 2 - 7 } & \multicolumn{1}{|c|}{$\mathbf{R}^{\mathbf{2}}$} & \multicolumn{1}{|c|}{ NSE } & \multicolumn{1}{c|}{ RSR } & \multicolumn{1}{|c|}{$\mathbf{R}^{\mathbf{2}}$} & \multicolumn{1}{c|}{ NSE } & \multicolumn{1}{c}{ RSR } \\
\hline 1000 & 0.65 & 0.19 & 1.62 & 0.35 & 0.30 & 0.87 \\
\hline 500 & 0.67 & 0.20 & 1.62 & 0.47 & 0.41 & 0.79 \\
\hline 200 & 0.70 & 0.20 & 1.62 & 0.63 & 0.57 & 0.67 \\
\hline 100 & 0.71 & 0.21 & 1.62 & 0.74 & 0.69 & 0.56 \\
\hline 50 & 0.72 & 0.21 & 1.62 & 0.82 & 0.79 & 0.46 \\
\hline 20 & 0.73 & 0.21 & 1.63 & 0.87 & 0.87 & 0.36 \\
\hline 10 & 0.73 & 0.21 & 1.64 & 0.89 & 0.89 & 0.33 \\
\hline
\end{tabular}

Table 4. Comparison of validation results (observed vs simulated surge levels fitted to Generalized Pareto distribution).

There are also visible differences in the outcomes of the climate change simulations compared to [26]. For instance, our results predict that extreme surges will mostly become lower in the Baltic Sea, opposite to the findings of the JRC study. On the other hand, JRC forecast a decrease in surge heights in most of the Iberia and British Isles, in contrast to this study, which mostly indicated increases. The difference may be large caused by different source of climate data, which in the case of the JRC study was a coarsely-gridded ensemble of global models, whereas this study utilized high-resolution regional projections.

The database presented here could have many applications. Mostly importantly, it will be used to create flood hazard maps in a follow-up study. To calculate the flood zones, a "bathtub fill" method will be applied [56]. In this approach, it is assumed that all land laying below a defined sea level is flooded, as long as it is hydrologically connected with the sea. It is planned to perform a correction of the EU-DEM to increase accuracy of the maps, as well as validate the results based on highresolution local studies.

Finally, the results of the study could be used in a statistical analysis of dependencies of surges between different parts of Europe. Example of such a calculation is presented in Fig. 10. Daily maxima of surges in each of the selected localities are highly correlated with coastal segments in a range of several hundred kilometres. Modelling those dependencies through copulas could be an alternative to regional frequency analysis. The data from our study indicated mostly the existence of uppertail dependence of surge levels, though often a normal (Gaussian) copula was a good model as well (i. e., with no tail dependence). Rarely, however, an lower-tail dependence was observed. These aspects require further investigation.

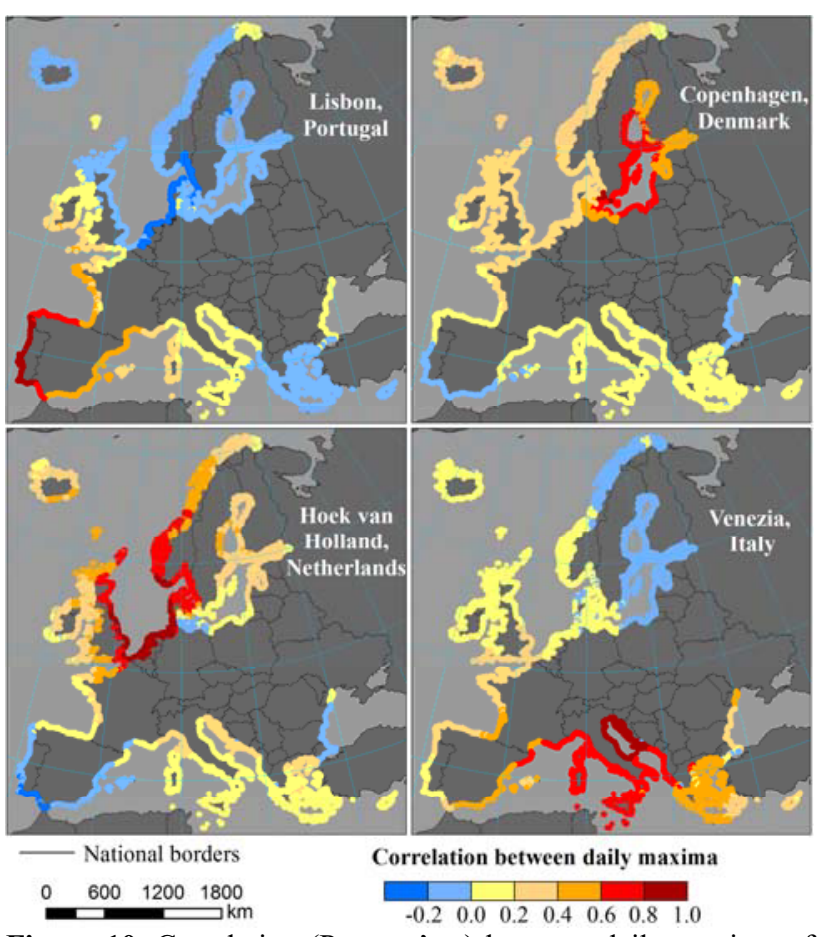

Figure 10. Correlation (Pearson's $r$ ) between daily maxima of storm surges in the indicated station and all other coasts in Europe. Calculation made using ERA-Interim simulation results (1979-2014)

\section{Conclusions}

In this paper we presented current and predicted water levels along European coasts, utilizing climate data with high temporal and spatial resolution. We have shown that using both climate reanalysis (ERA-Interim) and climate model control run (EURO-CORDEX), extreme storm surges could be accurately simulated in a hydrodynamic model. Also, the results are an added value compared to existing studies, as it has higher accuracy and incorporates a larger number of scenarios than studies available at time of writing.

Sea levels under climate change have very diversified trends across different locations in Europe. Change in mean levels has the largest impact in most areas. They will be compensated by ground uplift in Scandinavia, and by decrease in surge height in many other places. However, in areas where surges are small, such as the Mediterranean and Black seas, the extreme water levels can even double. Those results will be further investigated in the form of flood hazard maps, and an analysis of statistical dependencies between different parts of the coast.

\section{Acknowledgments}

This work was supported by European Union's Seventh Framework Programme under "Risk analysis of infrastructure networks in response to extreme weather" (RAIN) project, grant no. 608166. The authors would like to thank Michalis Vousdoukas and Evangelos Voukouvalas for kindly sharing data from the Joint Research Centre's work on storm surges and some useful 
comments, and Aimée Slangen for supplying data from her study on regional sea level rise. The harmonic analysis was done using a code by Aslak Grinsted.

\section{References}

1. Barredo J. I. (2007). Major flood disasters in Europe: 1950-2005. Natural Hazards, 42(1), 125-148.

2. Lumbroso D. M. and Vinet F. (2011). A comparison of the causes, effects and aftermaths of the coastal flooding of England in 1953 and France in 2010. Natural Hazards and Earth System Sciences, 11(8), 2321-2333.

3. Church J. A., Clark P. U., Cazenave A., Gregory J. M., ... and Unnikrishnan A. S. (2013). Sea Level Change. Climate Change 2013: The Physical Science Basis Contribution of Working Group I to the Fifth Assessment Report of the Intergovernmental Panel on Climate Change, Cambridge University Press, Cambridge and New York, pp. 1137-1216.

4. Sterl A., van den Brink H., de Vries H., Haarsma R. and van Meijgaard E. (2009) An ensemble study of extreme storm surge related water levels in the North Sea in a changing climate. Ocean Science, 5(4), 369378.

5. Hunter J. (2010). Estimating sea-level extremes under conditions of uncertain sea-level rise. Climatic Change, 99, 331-350.

6. Wróblewski A. (1994). Analysis and forecast of long-term sea level changes along the Polish Baltic Sea coast. Part II. Annual mean sea levels - forecast to the year 2100. Oceanologia, 36, 107-120

7. Xu S. and Huang W. (2013). Effects of sea level rise on frequency analysis of $1 \%$ annual maximum water levels in the coast of Florida. Ocean Engineering, 71, 96-102.

8. Church J. A. and White N. J. (2011). Sea-Level Rise from the Late 19 th to the Early 21 st Century. Surveys in Geophysics, 32, 585-602.

9. NOAA (2015). Sea Level Rise. Laboratory for Satellite Altimetry, http://www.star.nesdis.noaa.gov/ sod/lsa/SeaLevelRise, last accessed 6 Dec 2015.

10. Peltier W. R. (2001). Global glacial isostatic adjustment and modern instrumental records of relative sea level history. Sea Level Rise History and Consequences, International Geophysics, 75, Leatherman, pp. 65-95.

11. Peltier W. R., Argus D. F. and Drummond R. (2015). Space geodesy constrains ice-age terminal deglaciation: The global ICE-6G_C (VM5a) model. Journal of Geophysical Research: Solid Earth, 120(1), 450-487.

12. Slangen A. B. A., van de Wal R. S. W., Wada Y. and Vermeersen L. L. A. (2014). Comparing tide gauge observations to regional patterns of sea-level change (1961-2003). Earth System Dynamics, 5(6), 243255.

13. Wolski T., Wiśniewski B., Giza A., KowalewskaKalkowska H., ... and Lydeikaite Ž. (2014). Extreme sea levels at selected stations on the Baltic Sea coast. Oceanologia, 56(2), 259-290.
14. SHOM (2012) Statistiques des niveaux marins extrêmes des côtes de France (Manche et Atlantique),

http://refmar.shom.fr/fr/sea_level_news_2013/t1/stati stiques-2012-des-niveaux-marins-extremes-descotes-de-france-manche-et-atlantique, last accessed 7 December 2015.

15. Hosking, J. R. M. and Wallis, J. R. (1997). Regional Frequency Analysis - An approach based on Lmoments, Cambridge University Press, Cambridge.

16. Bardet L., Duluc C.-M., Rebour V. and L'Her J. (2011). Regional frequency analysis of extreme storm surges along the French coast. Natural Hazards and Earth System Sciences, 11(6), 16271639.

17. Bernardara P., Andreewsky M. and Benoit $M$. (2011). Application of regional frequency analysis to the estimation of extreme storm surges. Journal of Geophysical Research, 116, C02008.

18. Van Gelder P. H. A. J. M. and Mai C. V. (2008). Distribution functions of extreme sea waves and river discharges. Journal of Hydraulic Research, 46(2), 280-291.

19. Sebastião P., Soares C. G. and Alvarez E. (2008). 44 years hindcast of sea level in the Atlantic Coast of Europe. Coastal Engineering, 55(11), 843-848.

20. Batstone C., Lawless M., Tawn J., Horsburgh K., ... and Hunt T. (2013). A UK best-practice approach for extreme sea-level analysis along complex topographic coastlines. Ocean Engineering, 71, 2839.

21. Arns A., Wahl T., Haigh I. D. and Jensen J. (2015). Determining return water levels at ungauged coastal sites: a case study for northern Germany. Ocean Dynamics, 65(4), 539-554.

22. Hinkel J., Nicholls R. J., Vafeidis A. T., Tol R. S. J. and Avagianou T. (2010). Assessing risk of and adaptation to sea-level rise in the European Union: an application of DIVA. Mitigation and Adaptation Strategies for Global Change, 15(7), 703-719.

23. Vafeidis A. T., Nicholls R. J., McFadden L., Tol R. S. J., ... and Klein R. J. T. (2008). A New Global Coastal Database for Impact and Vulnerability Analysis to Sea-Level Rise. Journal of Coastal Research, 24(4), 917-924.

24. Mokrech M., Kebede A. S., Nicholls R. J., Wimmer F., Feyen L. (2015). An integrated approach for assessing flood impacts due to future climate and socio-economic conditions and the scope of adaptation in Europe. Climatic Change, 128(3), 245260.

25. Muis S., Verlaan M., Winsemius H., Aerts J. C. J. H. and Ward P. J. (2015). The first global-scale hindcast of extreme sea levels. E-proceedings of the 36th IAHR World Congress, The Hague, the Netherlands.

26. Vousdoukas M. I., Voukouvalas E., Annunziato A., Giardino A. and Feyen L. (2015). Projections of extreme storm surge levels along Europe. Climate Dynamics (submitted).

27. Paprotny D. and Morales-Nápoles O. (2015) A Bayesian Network for extreme river discharges in Europe. Safety and Reliability of Complex 
Engineered Systems, CRC Press/Balkema, 43034311.

28. Jacob D., Petersen J., Eggert B., Alias A., ... and Yiou P. (2014). EURO-CORDEX: new highresolution climate change projections for European impact research. Regional Environmental Change, 14(2), 563-578.

29. Dee D. P., Uppala S. M., Simmons A. J., Berrisford, P., ... and Vitart F. (2011). The ERA-Interim reanalysis: configuration and performance of the data assimilation system. Quarterly Journal of the Royal Meteorological Society, 137, 553-597.

30. Strandberg G., Bärring L., Hansson U., Jansson C., ..., Wang S. (2014). CORDEX scenarios for Europe from the Rossby Centre regional climate model RCA4. Report Meteorology and Climatology No. 116, SMHI, Norrköping, Sweden.

31. Moss R., Babiker M., Brinkman S., Calvo E., ... and Zurek M. (2008). Towards New Scenarios for Analysis of Emissions, Climate Change, Impacts, and Response Strategies, Intergovernmental Panel on Climate Change, Geneva.

32. EMODnet (2015). Portal for Bathymetry, http://portal.emodnet-bathymetry.eu/, last accessed 14 Dec 2015.

33. Charnock H. (1955). Wind stress on a water surface. Quarterly Journal of the Royal Meteorological Society, 81, 639-640.

34. Fourcy D. and Lorvelec O. (2013). A new digital map of limits of oceans and seas consistent with high-resolution global shorelines. Journal of Coastal Research, 29(2), 471-477.

35. UHLSC (2015). Research Quality. http://uhslc.soest.hawaii.edu/data/download/rq, last accessed 11 Dec 2015.

36. BODC (2015). International sea level, https://www.bodc.ac.uk/data/online_delivery/internat ional_sea_level/, last accessed 12 Dec 2015.

37. SMHI (2015). SMHI Öppna data, http://opendatacatalog.smhi.se/explore/. Last accessed 11 December 2015.

38. Rijkswaterstaat (2015). Waterbase, http://live.waterbase.nl/, last accessed 11 December 2015.

39. Wiśniewski B. and Wolski T. (2009). Katalogi wezbrań $i$ obniżeń sztormowych poziomów morza oraz ekstremalne poziomy wód na polskim wybrzeżu, Maritime University of Szczecin, Szczecin.

40. McMillan A., Batstone C., Worth D., Tawn J., Horsburgh K. and Lawless M. (2011). Coastal flood boundary conditions for UK mainland and islands, Environment Agency, Bristol.

41. Moriasi D., Arnold J., Van Liew M., Binger R., Harmel R. and Veith T. (2007). Model evaluation guidelines for systematic quantification of accuracy in watershed simulations. Transactions of the $A S A B E$, 50(3), 885-900.

42. Arns A., Wahl T., Haigh I. D., Jensen J. and Pattiaratchi C. (2013). Estimating extreme water level probabilities: A comparison of the direct methods and recommendations for best practise. Ocean Engineering, 81, 51-66.
43. Haigh I. D., Nicholls R. and Wells N. (2010). A comparison of the main methods for estimating probabilities of extreme still water levels. Coastal Engineering, 57(9), 838-849.

44. Mutua F. M. (1994). The use of the Akaike Information Criterion in the identification of an optimum flood frequency model. Hydrological Sciences Journal, 39(3), 235-244.

45. Joe H. 2014. Dependence Modeling with Copulas, Chapman \& Hall/CRC, London.

46. Egbert G. D., Bennett A. F. and Foreman M. G. G. (1994). Topex/Poseidon tides estimated using a global inverse model. Journal of Geophysical Research, 99(C12), 24821-24852.

47. Stammer D., Ray R. D., Andersen O. B., Arbic B. K., ... and Yi Y. (2014). Accuracy assessment of global barotropic ocean tide models. Reviews in Geophysics, 52(3), 243-282.

48. Pickering M. D., Wells N. C., Horsburgh K. J., Green J. A. M. (2012). The impact of future sea-level rise on the European shelf tides. Continental Shelf Research, 35, 1-15.

49. Aviso (2015). Combined mean dynamic topography, http://www.aviso.altimetry.fr/en/data/products/auxili ary-products/mdt.html, last accessed 15 Dec 2015.

50. Rio M.-H., Mulet S. and Picot N. (2014). Beyond GOCE for the ocean circulation estimate: Synergetic use of altimetry, gravimetry, and in situ data provides new insight into geostrophic and Ekman currents. Geophysical Research Letters, 41(24), 8918-8925.

51. Voldoire A., Sanchez-Gomez E., Salas y Mélia D., Decharme B., ... and Chauvin F. (2013). The CNRM-CM5.1 global climate model: description and basic evaluation. Climate Dynamics, 40(9), 20912121.

52. Slangen A. B. A., Carson M., Katsman C. A., van de Wal R. S. W., ... and Stammer D. (2014). Projecting twenty-first century regional sea-level changes. Climatic Change, 124(1), 317-332.

53. Carson M., Koehl A., Stammer D., Slangen A. B. A., ... and White N. (2016). Coastal Sea Level Changes, Observed and Projected during the 20th and 21st Century. Climatic Change, 134(1), 269-281.

54. De Jager A. L. and Vogt J. V. (2010). Development and demonstration of a structured hydrological feature coding system for Europe. Hydrological Sciences Journal, 55(5), 661-675.

55. Lilje M. (2004). Changing the Geodetic Infrastructure. FIG Working Week 2004, Athens, Greece, May 22-27, 2004.

56. Poulter B. and Halpin P. N. (2008). Raster modelling of coastal flooding from sea-level rise. International Journal of Geographical Information Science, 22(2), 167-182. 